\title{
Water-loss dehydration and aging
}

Lee Hooper ${ }^{\mathrm{a}}$, Diane Bunn ${ }^{\mathrm{a}}$, Florence Jimoh ${ }^{\mathrm{a}}$, Susan J Fairweather-Tait ${ }^{\mathrm{a}}$.

${ }^{a}$ Norwich Medical School, University of East Anglia, Norwich Research Park, Norwich NR4 7TJ, Norfolk, UK.

Lee Hooper: 1.hooper@uea.ac.uk, +44(0)1603591268

Diane Bunn: d.bunn@uea.ac.uk

Florence Oluseyi Jimoh: fjimoh2011@gmail.com

Susan J Fairweather-Tait: $\underline{\text { s.fairweather-tait@uea.ac.uk }}$

Corresponding author: Lee Hooper

This report is independent research arising from a Career Development Fellowship supported by the National Institute for Health Research and has received funding from the Seventh Framework Programme (FP7/2007-2013) under grant agreement n. 266486 (NU-AGE project entitled "New dietary strategies addressing the specific needs of elderly population for a healthy ageing in Europe"), ClinicalTrials.gov Identifier: NCT01754012. The views expressed in this publication are those of the author(s) and not necessarily those of the NHS, the National Institute for Health Research or the Department of Health. 


\begin{abstract}
This review defines water-loss and salt-loss dehydration. For older people serum osmolality appears the most appropriate gold standard for diagnosis of water-loss dehydration, but clear signs of early dehydration have not been developed. In older adults, lower muscle mass, reduced kidney function, physical and cognitive disabilities, blunted thirst, and polypharmacy all increase dehydration risk. Cross-sectional studies suggest a water-loss dehydration prevalence of 20-30\% in this population. Water-loss dehydration is associated with higher mortality, morbidity and disability in older people, but evidence is still needed that this relationship is causal. There are a variety of ways we may be able to help older people reduce their risk of dehydration by recognising that they are not drinking enough, and being helped to drink more. Strategies to increase fluid intake in residential care homes include identifying and overcoming individual and institutional barriers to drinking, such as being worried about not reaching the toilet in time, physical inability to make or to reach drinks, and reduced social drinking and drinking pleasure. Research needs are discussed, some of which will be addressed by the FP7-funded NU-AGE (New dietary strategies addressing the specific needs of elderly population for a healthy ageing in Europe) trial.
\end{abstract}

Keywords: dehydration, osmolar concentration, drinking, aged

\title{
Highlights
}

- $20-30 \%$ of older people have water-loss dehydration

- Dehydration is associated with increased mortality, morbidity and disability.

- Vulnerability to dehydration is associated with ageing.

- Relationships between fluid intake and hydration status will be examined in NU-AGE

- NU-AGE will describe drinking and dietary patterns associated with good hydration 


\section{Introduction}

As we age the proportion of fluid in our bodies reduces, from over $70 \%$ of our weight as newborn babies, to $60 \%$ in childhood and about $50 \%$ in older people (Altman, 1961;Friis-Hansen et. al., 1951;Greenleaf, 1998;Olde Rikkert et. al., 1997). As body water falls with age, the buffering capacity against dehydration is reduced, which can have serious consequences to health and wellbeing (Olde Rikkert et. al., 2009). According to Aristotle, over 2000 years ago, "old age is dry and cold" (Aristotle, 350 B.C.).

Water is central to every activity of the human body. Life arose in the water, and every human being starts life in utero in a watery environment, but humans are land creatures who have to carry their watery environment around inside them. The aqueous intracellular environment is essential for biochemical processes, and water is central for the maintenance of the circulation, the lymphatic system, body temperature, removal of waste products from cells and from the body, facilitating ingestion and digestion, acting as a lubricant, and flushing out the urinary tract, eyes and other crucial organs. In the absence of fluid intake death occurs in a few days to a week, far more quickly than due to the absence of any other nutrient.

\subsection{Definition of water-loss dehydration and salt-loss dehydration}

There are several types of dehydration, with distinct causes and treatments. The Dehydration Council defines dehydration as "a complex condition resulting in a reduction in total body water" and suggests that the main types are water-loss dehydration and salt-loss dehydration (Thomas et. al., 2008), while EFSA calls it "the process of losing body water and leads eventually to hypohydration (the condition of body water deficit)" (EFSA Panel on Dietetic Products, 2010). Water-loss (or hypertonic) dehydration is due to insufficient fluid intake and results in raised serum osmolality (raised 
concentrations of minerals and small molecules in serum, measured by a depressed freezing point of serum). Salt-loss (or hypotonic) dehydration is due to deficits of both salt and water, which may follow excessive diarrhoea, vomiting, blood loss or sweating, thus serum osmolality and serum sodium are low.

\subsection{The reference (or gold) standard for dehydration}

There are a variety of ways that physicians and scientists may determine whether an individual is truly dehydrated, and there has been debate about the best measure(s), the gold standard or reference standard, to use (Armstrong, 2007). Potential reference standards for dehydration include:

- Plasma urea/creatinine ratio, which appears useful when kidneys function well, but in older populations raised ratios may also be due to renal failure, bleeding, heart failure, sarcopenia, glucocorticoids or high intakes of protein, making it unhelpful in the specific diagnosis of dehydration (American Medical Directors Association (AMDA), 2009; Thomas et al., 2008).

- Physician assessment of dehydration has been used as a gold standard for dehydration diagnosis, but there is good evidence that this may not correlate with the biochemical assessment of dehydration. This was hypothesised as being because physicians use unreliable signs in making diagnoses (Thomas et. al., 2003).

- Bioelectrical impedance may be useful in calculating total body water, but does not appear to be sufficiently accurate under conditions of change in hydration status and when body compartments are undergoing acute changes as changes in the ratio of intra- to extra-cellular water, and of acute changes in these compartments, as these also influence resistivity (Kafri et. al., 2013;Kyle et. al., 2004;Olde Rikkert et al., 1997) 
- Change in body weight may be helpful in diagnosing rapid dehydration or re-hydration. Total body weight is the sum of body fluid, fat, muscle, organs and bone, and the weight of body fluid is difficult to disentangle from total weight. However, fluid is the body component with the ability to alter most quickly, so that a substantial change in body weight over a few days will relate most directly to fluid status (Cheuvront et. al., 2010;Shirreffs, 2003). For this reason a reduction of $\geq 4 \%$ (EFSA Panel on Dietetic Products, 2010) of body weight within 7 days may be considered to be a clear sign of dehydration, as would an increase of $\geq 4 \%$ of body weight on rehydration (again within 7 days). This relies on more than one assessment (so cannot be measured instantly), the assessments need to be accurate and take issues like constipation, oedema etc into account, and screening for dehydration will only pick up rapid dehydration, rather than a slow decline leading towards dehydration (Cheuvront et al., 2010).

- While total body water (TBW) can be estimated by deuterium oxide dilution (or even more accurately by cadaver analysis), so that change in TBW can be assessed over time (Olde Rikkert et. al., 1998;Schloerb et. al., 1950), no single measure of TBW, or the extracellular or intracellular fluid compartments, has been correlated with hydration status in older people (Olde Rikkert et al., 1998).

- Serum measures, such as osmolality, osmolarity, sodium and tonicity (defined in box 1) have an advantage in that they only require a single measurement (although they can be followed serially). These parameters are carefully controlled by the body and any change suggests important problems in body biochemistry. Serum osmolality appears useful as a marker of water-loss dehydration when tested on a single occasion in young adults, having appropriate levels of analytic variation and an area under the curve of 0.95 (for a cut-off of 297 $\mathrm{mOsm} / \mathrm{kg}$, with sensitivity of $90 \%$ and specificity of $100 \%$ in young adults dehydrated via exercise in a hot environment and losing 2-7\% of their body weight) (Cheuvront et al., 2010). Serum sodium is less useful as an indicator of dehydration than serum osmolality as it alters 
by a smaller amount on dehydration (Institute of Medicine, 2004). Urea is a component of osmolality and osmolarity, but not tonicity. As urea can move freely between the intracellular and extracellular fluids it does not drive cellular dehydration (unlike the other components of osmolality and osmolarity) so tonicity may be particularly helpful in defining dehydration (Stookey, 2005).

Overall, there are clear benefits of using serum osmolality as a definitive diagnosis (reference standard) for water-loss dehydration, as serum and intracellular osmolality are so central to body fluid control that they act as a trigger to both thirst and renal conservation of fluid (Naitoh and Burrell, 1998). Its strengths include the ability to diagnose hydration status at a single time point, without prior information about the individual. For these reasons serum osmolality has been adopted most often as the reference standard for dehydration in older adults (Cheuvront et. al., 2013;Thomas et al., 2008). The US Panel on Dietary Reference Intakes for Electrolytes and Water stated "The primary indicator of hydration status is plasma or serum osmolality" (Institute of Medicine, 2004).

\subsection{Signs of dehydration in older people}

Although serum osmolality defines the state of water-loss dehydration (is the gold standard), it would be helpful to be able to use simple indicative signs of early dehydration in older people to alert older people and their carers to impending dehydration. This is because regular blood tests are not feasible or practical in the community or residential care settings (Leibovitz et. al., 2007), results may take some time to arrive and can be costly. Such signs would allow dehydration to be recognised simply in the community and non-clinical settings such as lunch clubs and care homes. We need to be able to recognise the early stages of water-loss dehydration so that we can help older people to drink more before their health is affected, and also recognise later stage dehydration when urgent action needs to be taken to prevent collapse from serious dehydration. 
In children (where there is more research than in older people) a systematic review of the diagnostic accuracy of signs suggested that capillary refill time, abnormal skin turgor and abnormal respiratory pattern were the most useful signs in predicting dehydration (loss of 5\% of body weight), and that combinations of these were better than individual signs (Steiner et. al., 2004). A clinical dehydration scale that scored for general appearance, sunken eyes, moist, sticky or dry tongue and present or absent tears in children aged 1 month to 5 years with acute gastroenteritis was able to predict length of stay and need for intravenous rehydration (Friedman et. al., 2004;Goldman et. al., 2008). An earlier study of children of the same ages with diarrhoea, vomiting or poor oral intake found that a combination of at least 2 signs of 4 (slow capillary refill, absence of tears, dry mucous membranes, ill appearance) was highly diagnostic, with an area under the curve of 0.90 , and three or more of 10 signs (decreased skin elasticity, slow capillary refill, general appearance, absent tears, abnormal breathing, dry mucous membranes, sunken eyes, abnormal radial pulse, tachycardia or decreased urine output) was $87 \%$ sensitive and $82 \%$ specific (area under the curve of 0.91 ) for fluid deficit of $5 \%$ of weight (Gorelick et. al., 1997).

We cannot use these signs of dehydration in children directly in older people, without checking that they are truly diagnostic, for a variety of reasons. Some of the signs, such as decreased skin elasticity and sunken eyes, become more common in older people as part of the ageing process. Dry mucous membranes may be a sign that an older person has a cold and is breathing through their mouth, may indicate use of medication that dries out the mouth (some blood pressure medications, antihistamines, antidepressants, diuretics or non-steroidal anti-inflammatory drugs for example), or relate to chronic illness such as rheumatoid arthritis or lupus - dehydration is not the only or even the most likely cause of a dry mouth. Additionally, we need to be able to pick up the early stages of dehydration in older people, rather than looking for signs of acute and serious dehydration - so that they can be helped to increase their drinking and avoid any health ill-effects (Cheuvront et al., 2013). 
Considering the physiology of dehydration there are certain signs that may help identify it. The reduction in cell volume could be indicated by signs such as confusion, headache, lethargy, dizziness, dry wrinkled skin and/or reduced skin turgor. A resulting reduction in fluid excretion could be recognised by infrequent, dark or concentrated urine, dry lips, dry mouth, low saliva flow, dry eyes, dry armpits or palms. Low blood volume might be identified via slow capillary refill, low blood pressure, weak pulse, rapid heartbeat or orthostatic hypotension. A systematic review of the diagnostic accuracy of physical signs of hypovolaemia, which included studies published to late 1997, found that in the few relevant studies there was limited evidence that in older people with vomiting, diarrhoea or reduced fluid intake that dry armpits (axilla) supported the diagnosis of hypovolaemia (positive likelihood ratio $2.8,95 \%$ CI 1.4 to 5.4 ), and moist mucous membranes or a tongue without furrows supported lack of hypovolaemia (negative likelihood ratio for each $0.3,95 \%$ CI 0.1 to 0.6). Capillary refill time and poor skin turgor (elasticity) were not found to be diagnostic (McGee et. al., 1999). An Australian cohort study found that the fall in systolic blood pressure on standing, sternal skin turgor, tongue dryness and body mass index were good indicators of early dehydration on hospital admission. However, these factors were compared with physician assessment of hydration status, and the physician assessments may have included some or all of the clinical signs, so that the two assessments were not necessarily independent (Vivanti et. al., 2008).

A recent small study of 27 older Japanese people (mean age 86) with acute medical conditions assessed signs of dehydration (defined as calculated osmolarity, although called osmolality, >295mOsm/L), and found that of dry axilla, dry mouth, reduced skin turgor, sunken eyes and delayed capillary refill dry axilla (underarm) was the most sensitive (44\%) and specific (89\%, with a diagnostic odds ratio of 4.0), while sunken eyes and slow capillary refill showed some diagnostic tendencies (Shimizu et. al., 2012). Other single-assessment methods proposed to diagnose dehydration include assessment of urine colour, urine specific gravity, saliva osmolality, urine volume, sunken eyes, dry eyes and raised tear osmolarity, rapid pulse, postural pulse 
increment, severe postural dizziness, fluid balance charts, upper body weakness, bioelectrical impedance, and checklists of risk factors (Cheuvront et al., 2010;Gross et. al., 1992;Mentes, 2006; Mentes et. al., 2006;Schut et. al., 2005;Thomas et al., 2008;Vivanti et al., 2008;Walsh et. al., 2012).

A systematic review that searched literature to 1995 found that early diagnosis of dehydration in older adults can be difficult because "the classical physical signs of dehydration may be absent or misleading in an older patient" suggesting that even index tests established in younger people cannot be assumed to be useful in older people (Weinberg et. al., 1995). Although some tests are probably not useful in older people, others may indicate dehydration risk, early stages of dehydration, or current dehydration. It is likely that a portfolio of assessments would be needed to usefully assess stage and type of dehydration among people in residential care without indicating that all residents are at high risk (Olde Rikkert et al., 1998; Wotton et. al., 2008).

Our team is carrying out a Cochrane systematic review of the diagnostic accuracy of simple physical signs compared to serum osmolality in older people (the protocol is published (Hooper et. al., 2011)). Early analyses suggest that promising clinical and physical signs include dry oral mucosa, poor cognition, raised body temperature, low fluid intake, low urine volume and possibly urine colour, axillial sweating and foot vein filling, but none of these signs appear diagnostically accurate enough to be used as single markers of dehydration in older people. As the published literature in this area is too limited to allow theoretical development of a tool involving more than one sign, we have begun a primary study to assess a multitude of possible signs of dehydration against serum osmolality (the blood sample taken within 2 hours of the signs) in 200 elderly care home residents in Norfolk (see http://driestudy.appspot.com/ for details, including the study protocol). From the dataset for this study we will check whether any single sign is diagnostic in its own right, and if not, aim to develop a short sequence of simple signs that will allow us to diagnose early water-loss dehydration. 


\subsection{Prevalence of dehydration in older people}

Salt-loss dehydration is present in 0.5 to $2 \%$ of free-living population samples of US people aged at least 70 years (defined in these studies as serum tonicity $<285 \mathrm{mmol} / \mathrm{L}$ or low serum tonicity plus orthostatic hypotension) (Stookey, 2005; Stookey et. al., 2005). The proportions of elderly people in these cohorts with water-loss dehydration were much higher, with $21 \%$ of the $70+$ year olds in the Duke component of the Established Populations for Epidemiologic Studies of the Elderly (EPESE) cohort (Stookey et al., 2005) and 28\% of the 70-90 years olds in the US National Health and Nutrition Examination Survey (NHANES) III cohort (Stookey, 2005) found to have current water-loss dehydration (defined as serum tonicity of at least $300 \mathrm{mmol} / \mathrm{L}$ ). As tonicity can be raised due to high glucose levels, signifying poor glucose regulation, as well as the result of increased minerals which would suggest insufficient fluid intake, the proportion of raised tonicity due to raised glucose was examined in the EPESE cohort; $23 \%$ of people with raised tonicity also had raised serum glucose (here defined as serum glucose of at least $200 \mathrm{mg} / \mathrm{dl}$ ), suggesting that dehydration due to insufficient fluid intake was present in $16 \%$ of these older adults (Stookey et al., 2005).

In the NHANES III cohort data were compared for different age-bands, suggesting that the proportion of adults with water-loss dehydration increases with age, from around $16 \%$ of 20-29 year olds, to $26 \%$ of $50-69$ year olds and $28 \%$ of $70-90$ year olds. Dehydration was more common in men of all ages (23\% in men aged 20-90) than women of the same age range (16\%) (Stookey, 2005). Rates of hospitalisation with dehydration in US elderly were higher in black men than in black women, and in white men than in white women, and higher in blacks of either gender than in whites of either gender (Warren et. al., 1994). 
Elderly adults in residential care have been considered to be a population at high risk of dehydration. A Californian nursing home study found that $31 \%$ of residents were dehydrated (11\% of elderly residents were hospitalised for dehydration, $6 \%$ were given intravenous rehydration, and $14 \%$ were found to have blood urea nitrogen/creatinine ratio greater than $25 \mathrm{mg} / \mathrm{dL}$ ) at some point over six months (Mentes, 2006). There is limited data on dehydration in the elderly in Europe, but preliminary analysis of 188 participants in our own study on dehydration in care home residents in Norfolk, England suggested that 20\% had current water-loss dehydration (defined as having serum osmolality of over $300 \mathrm{mOsm} / \mathrm{kg}$ ) and a further $28 \%$ had impending dehydration (serum osmolality of 295-300 mOsm/kg) (Hooper, unpublished, protocol available at http://driestudy.appspot.com/cohort.html). Men again appeared more likely to have current waterloss dehydration $(25 \%)$ than women $(17 \%)$ in this primarily Caucasian group, despite their slightly better health status in UK care homes (with marginally greater grip strength and mid-upper arm circumference (Kenkmann et. al., 2010)), but the difference was not statistically significant in this small sample. However, 34\% of those with cognitive impairment (Mini-Mental State Exam scores of 0-18) had current dehydration, significantly more than the $14 \%$ of those with less impaired cognition $(\mathrm{p}=0.005)$, confirming Seymour's finding of a "definite statistical association between high degrees of dehydration/volume depletion and poor mental function" in 71 elderly people emergency admissions to a general medical unit (Seymour et. al., 1980).

\subsection{Why older people are more at risk of water-loss dehydration}

All land animals need to be able to regulate their hydration levels in order to survive. In humans, drinking less leads to a rise in sodium levels in the extracellular fluid. To equalise the osmolality between the intracellular ( $67 \%$ of total body water) and extracellular (33\% of total body water) fluids there is a movement of water from within cells into the extracellular fluid, causing the osmolality of 
the intracellular fluid to rise and cells to shrink. Cellular osmoreceptors in the organum vasculosum of the lamina terminalis pick up this change and work to stimulate thirst (to increase drinking) and stimulate vasopressin secretion (also called anti-diuretic hormone, ADH) to reduce water loss(Figure 1). Vasopressin conserves water loss by stimulating the medulla within the kidney to produce more highly concentrated urine by increasing the permeability of the collecting ducts.

This elegant process of ensuring adequate hydration can break down somewhat as people age. One reason is that the fluid reserve is smaller, so dehydration can happen more quickly with water depletion (Olde Rikkert et al., 1997;Olde Rikkert et al., 2009). Fat free mass, and particularly muscle, are rich stores of fluid, around $70 \%$ water (fat tissue is $10-40 \%$ water), but as muscle mass decreases with ageing, the fluid reserve is reduced (Martin et. al., 1994).

Loss of fluid may not be as well controlled in old age. Kidney function decreases with age, so that the ability to concentrate urine and so retain fluid falls (Davies et. al., 1995;Lindeman et. al., 1985). Davies and Shock found that effective renal blood flow fell from a mean of 1077 (SD 150) $\mathrm{cc} / \mathrm{min} / 1.73 \mathrm{~m}^{2}$ in nine $20-29$ year old men to 475 (SD 141) cc/min $/ 1.73 \mathrm{~m}^{2}$ in twelve $80-89$ year olds (Davies and Shock, 1950), while in another study 60-79 year olds had a 20\% reduction in maximum urine osmolality, and a $100 \%$ increase in minimum urine flow rate compared to $20-39$ year olds in a longitudinal study of ageing (Rowe et. al., 1976). This did not appear to be due to a problem with vasopressin release as men aged over 70 years had lower resting vasopressin levels than younger men (aged less than 40 years), but vasopressin levels rose faster on dehydration in older men (Davies et al., 1995). Work in rats suggests that renal vasopressin receptors (V2 receptors), and several aquaporins (water channel proteins) become less common in the medulla with age (Sands, 2009). If this is mirrored in humans it would explain reduced ability to concentrate urine with age.

This reduced ability to retain fluid by concentrating urine may mean that urinary markers of dehydration are less useful in older people, and dehydration risk can be exacerbated by the use of 
laxatives and diuretics, which are very common in older people, as well as a wide range of other medications (American Medical Directors Association (AMDA), 2009;Mentes, 2006). For example, diuretics were used by around a quarter of residents in Norfolk UK care homes (Kenkmann et al., 2010).

The thirst response is less effective with ageing as older people have to experience greater serum osmolality before thirst is stimulated, although they respond to thirst in the same way as younger people (Davies et al., 1995;Mack et. al., 1994). This means that relying on thirst to trigger drinking can lead to dehydration in older people, and drinking has to be driven by routine, social occasions and carers rather than thirst.

There are many reasons, other than lack of thirst, why older people may not drink enough to prevent dehydration, and these are discussed in the next section along with ideas about how care homes may be able to encourage older people to drink more.

\subsection{Helping older people to prevent dehydration}

In older people who are living in the community or in residential care and nursing homes issues surrounding drinking and eating (fluid supply) and urination (fluid removal) need to be addressed in order to promote optimal hydration. The areas that need to be considered are personal factors, habits and preferences; social and environmental conditions; and systems of care and support.

\section{$\underline{\text { Problems }}$}

Personal factors leading to dehydration may include lack of knowledge and misconceptions concerning the effects of drinking or not drinking, or the fact that this knowledge is overridden by other concerns. This is particularly relevant for residents who are afraid of incontinence and/or 
require help for the toilet, where drinking is often reduced in an attempt to minimise (what are seen to be) potential embarrassments and consequent loss of dignity (Godfrey et. al., 2012). Many care home residents informally describe limiting or avoiding drinks so that they need to ask for help to get to the toilet less often during the day or night. Communication problems may affect drinking overtly through dysphasia, loss of hearing or language barriers, where residents have difficulty verbalising their needs and preferences. Other personal barriers include poor taste sensation, which can be related to poor dental and oral health, low zinc status, comorbidities or medication use (Bourre, 2006; Solemdal et. al., 2012), as well as poor eyesight which affects the ability to see and locate a drink or drink-making facilities. For older people with dementia drinks may be forgotten, or people may be convinced they have had a recent drink.

Physical factors can lead to problems in accessing the type and number of drinks that are desired. In the community carrying heavy containers of milk or fruit juice home from the shops can be a problem. In residential homes there may not be facilities available for residents to make their own drinks, or where facilities are available, walking frames may make it difficult to transport a drink to a comfortable place to drink, and drinks that are provided may be left out of reach for a frail older person. If the resident is thirsty second helpings may not be offered.

Social and environmental conditions can be crucial in supporting eating and drinking as social occasions - people tend to eat and drink together whenever they meet, chat, bond, or share a hobby or experiences (Philpin et. al., 2011). Social contact is an important trigger for drinking (whether cups of tea or coffee, a glass of wine or a pint of beer) but social isolation is common in older people and can lead to a lack of shared drinks.

\section{$\underline{\text { Interventions }}$}

The availability and accessibility of a variety of hot and cold drinks may help to ensure that older people drink enough. In residential care the provision of jugs of water or other cold drinks (within 
reach), along with an appropriate cup (designed so that residents can lift the jug and cup themselves if possible, and including cups with spouts where these are helpful) should be normal practice. The Hydrant, is another such device, which enables the user to access water independently without having to lift a jug or beaker (Campbell, 2011). Use of the red-jug scheme, whereby residents or hospital patients at risk of dehydration are provided with water in red jugs, act as a constant alert to staff, families and the person themselves, that this person is high risk, and so should be offered drinks at every opportunity (Hollis, 2011). Red jugs are also easier to see for the visually impaired, and this alone may increase fluid intake, as failing eyesight has been identified as a contributory factor to poor drinking habits because drinks served in pale cups are hard to see. A small study in the USA demonstrated that drinks served in bright-coloured cups increased fluid intake (Dunne et. al., 2004).

Hot drinks also need to be available for residents to help themselves or offered regularly during the day, including between meals (Hodgkinson et. al., 2003). Providing a variety of drinks, served according to individual preference, promotes fluid intake by contributing to the overall pleasure of drinking (Godfrey et al., 2012;Robinson and Rosher, 2002).

Interventions to prevent dehydration due to personal factors might include education on the importance of good hydration and addressing the misconception that not drinking to avoid going to the toilet is harmless. In reality, not drinking leads to dehydration and a consequent increase in risk of poor health outcomes (see section 9). Efforts to facilitate the ease and speed of residents reaching the toilet whenever they need to is the more appropriate solution (Anglian Water Services, 2009). Communication problems should be addressed by diagnosing and treating hearing problems: ensuring translation facilities are available if required, and that there is training and support for staff to develop and take time for open and honest communication with residents. Regular health checks around oral health, general and nutritional health, and medication review with a focus on food and 
fluid intake and taste perception (involving dental, medical and pharmaceutical professionals) may be helpful in maintaining good taste and an appetite for eating and drinking. Similarly, involvement of the dietitian and speech therapist are essential to provide practical advice for people with dysphagia. Promoting the social aspect of drinking amongst care home residents may improve fluid intake and prevent dehydration(Gleibs et. al., 2011). The aesthetics of the environment may also help to ensure that drinking is a pleasurable experience, rather than a chore (Godfrey et al., 2012). Suggestions include smaller dining areas which are 'homely' with few institutionalised features and minimal distractions, where residents eat and drink in small, friendly and supportive groups (Dickinson et. al., 2008;Godfrey et al., 2012;Kenkmann et al., 2010). Ensuring a favourite cup or mug is used, providing a drink at the preferred temperature and taking taste and brand considerations into account may also help.

Systems of support and care can also affect hydration. There is some evidence that staffing numbers and the abilities of staff to assist effectively with drinking and toileting are major issues affecting fluid intake (Kayser-Jones et. al., 1999;Simmons et. al., 2001b). Prompting residents to finish drinks has been shown to increase drinking in cognitively-impaired older adults, but for older people with minimal cognitive impairment, prompting can have a negative effect on drinking, so the ability of staff to make subtle judgements may be important (Simmons et. al., 2001a). Staff training may also be crucial to ensure staff are aware of the importance of hydration in older people, are knowledgeable about how to monitor fluid intake or hydration status, and are able and willing provide appropriate assistance (Kayser-Jones et al., 1999;Ullrich and McCutcheon, 2008). Many authors have recommended the use of care packages involving detailed assessments of physical abilities (including swallowing and toileting), risk assessments, and the setting of goals regarding individual fluid requirements accompanied by appropriate monitoring procedures to achieve this (Wotton et al., 2008) . These would seem entirely appropriate, but, as with most potential interventions to promote hydration in older people, are as yet untested in rigorous research. Our 
group are carrying out a systematic review to assess which interventions have been shown to help older people living in long term care to drink well or prevent dehydration (Bunn and Hooper, 2012).

Preventing dehydration in residential care involves providing a setting that encourages drinking in all older people, recognising when an elderly person is not drinking enough, finding ways of encouraging older people who are not keen on drinking to increase their fluid intake, and possibly being able to provide hypodermoclysis if dehydration occurs as an alternative to admission to acute care for intravenous fluid administration. Hypodermoclysis is a method of giving fluid subcutaneously and is thought to be a safe way of administering fluid in long term care, although further research is needed to confirm this (Rochon et. al., 1997).

\subsection{How much older people drink and how we measure it}

The minimum fluid requirement for an individual has been defined as 'the amount of water that equals losses and prevents adverse effects of insufficient water' (EFSA Panel on Dietetic Products, 2010). Fluid is obtained from both food and drinks, but beverages (such as plain or flavoured water, tea, coffee, other hot drinks, milk and milk products, fruit juices, soft drinks and alcohol) account for 70-80\% of fluid intake in most populations (Bellisle et. al., 2010;Kant et. al., 2009).

There is no consensus of what constitutes adequate fluid intake in the elderly, and recommendations for fluid intake in adults have often been based on very small numbers of participants, studies in other mammals and recommendations for babies and children (Vivanti, 2012). Fluid recommendations vary between countries. The European Food Safety Authority recommended an Adequate Intake (AI) of 2.0L/day for women and 2.5L/day for men of all ages (from a combination of drinking water, beverages and food) (EFSA Panel on Dietetic Products, 2010), but these AIs differ from those of the World Health Organization, USA, and individual European countries (see Table 1). 


\begin{tabular}{|c|c|c|c|c|}
\hline \multirow{3}{*}{ Recommendations } & \multicolumn{2}{|c|}{ Daily total water* } & \multicolumn{2}{|c|}{ Daily drinks } \\
\hline & \multicolumn{2}{|c|}{ recommendations, $\mathrm{L}$} & \multicolumn{2}{|c|}{ recommendations, $\mathbf{L}$} \\
\hline & For women & For men & for women & for men \\
\hline Europe (EFSA Panel on Dietetic Products, 2010) & 2.0 & 2.5 & $1.6^{* *}$ & $2.0 * *$ \\
\hline World Health Organization (World Health & 2.2 & 2.9 & & \\
\hline \multicolumn{5}{|l|}{ Organization, 2005) } \\
\hline USA (Institute of Medicine, 2004) & 2.7 & 3.7 & 2.2 & 3.0 \\
\hline Belgium (Dupin et. al., 1992) & - & - & 1.5 & 1.5 \\
\hline UK (NHS Choices, 2011) & - & - & 1.2 & 1.2 \\
\hline Australia (Australian Government, 2006) & 2.8 & 3.4 & 2.1 & 2.6 \\
\hline Nordic Countries (NNR, 2012) & - & - & $1.0-1.5$ & $1.0-1.5$ \\
\hline
\end{tabular}

*Total water includes fluid from drinks and foods.

** EFSA AIs for drinks are here assumed to be $80 \%$ of AIs for daily total water based on their own assumption that $20 \%$ of total water in the diet is supplied by foods, however EFSA did not make a formal recommendation on drinks, only on total water.

The proportion of older people drinking enough to meet the standards depends on which standards are used, but intakes in older people are often low compared to standards (see Table 2). The SENECA study assessed total water intake in several European countries and found that $13-42 \%$ of men and $21-65 \%$ of women aged 75 to 86 in Europe had a total water intake of less than $1.7 \mathrm{~kg} / \mathrm{d}$. 
Table 2. Studies assessing the fluid intake of older people.

\begin{tabular}{|c|c|c|c|}
\hline Country (reference) & $\begin{array}{l}\text { Age, } \\
\text { years }\end{array}$ & $\begin{array}{l}\text { Intake of total water*, } \\
\text { mean (SD) }\end{array}$ & $\begin{array}{l}\text { Intake of drinks, mean } \\
\text { (SD) }\end{array}$ \\
\hline Belgium (Devriese et. al., 2006) & $60-74$ & & 1.39 L/d (SD unclear) \\
\hline Belgium (Haveman-Nies et. al., & $75-80$ & Men 2.24 kg/d (0.80) & \\
\hline 1997) & & Women $2.11 \mathrm{~kg} / \mathrm{d}(0.53)$ & \\
\hline Denmark (Haveman-Nies et al., & $75-80$ & Men $2.21 \mathrm{~kg} / \mathrm{d}(0.64)$ & \\
\hline 1997) & & Women $2.18 \mathrm{~kg} / \mathrm{d}(0.73)$ & \\
\hline France (Bellisle et al., 2010) & $>55$ & & $1.20 \mathrm{~L} / \mathrm{d}(0.43)$ \\
\hline France, Haguenau (Haveman- & $75-80$ & Men $2.32 \mathrm{~kg} / \mathrm{d}(0.62)$ & \\
\hline Nies et al., 1997) & & Women $2.15 \mathrm{~kg} / \mathrm{d}(0.59)$ & \\
\hline $\begin{array}{l}\text { France, Romans (Haveman-Nies } \\
\text { et al., 1997) }\end{array}$ & $75-80$ & $\begin{array}{l}\text { Men } 1.95 \mathrm{~kg} / \mathrm{d}(0.48) \\
\text { Women } 1.75 \mathrm{~kg} / \mathrm{d}(0.40)\end{array}$ & \\
\hline Germany (Manz et. al., 2012) & $\geq 65$ & $2.33 \mathrm{~L} / \mathrm{d}(0.54)$ & $1.27 \mathrm{~L} / \mathrm{d}(0.46)$ \\
\hline Italy (Haveman-Nies et al., 1997) & $75-80$ & $\begin{array}{l}\text { Men } 1.90 \mathrm{~kg} / \mathrm{d}(0.50) \\
\text { Women } 1.61 \mathrm{~kg} / \mathrm{d}(0.50)\end{array}$ & \\
\hline $\begin{array}{l}\text { The Netherlands (Haveman-Nies } \\
\text { et al., 1997) }\end{array}$ & $75-80$ & $\begin{array}{l}\text { Men } 2.24 \mathrm{~kg} / \mathrm{d}(0.48) \\
\text { Women } 2.19 \mathrm{~kg} / \mathrm{d}(0.62)\end{array}$ & \\
\hline $\begin{array}{l}\text { Poland (Pietruszka and } \\
\text { Krajewska, 2003) }\end{array}$ & $75-80$ & & $1.50 \mathrm{~kg} / \mathrm{d}(0.39)$ \\
\hline $\begin{array}{l}\text { Poland (Haveman-Nies et al., } \\
\text { 1997) }\end{array}$ & $75-80$ & $\begin{array}{l}\text { Men } 1.86 \mathrm{~kg} / \mathrm{d}(0.50) \\
\text { Women } 1.61 \mathrm{~kg} / \mathrm{d}(0.49)\end{array}$ & \\
\hline $\begin{array}{l}\text { Portugal (Haveman-Nies et al., } \\
\text { 1997) }\end{array}$ & $75-80$ & $\begin{array}{l}\text { Men } 2.11 \mathrm{~kg} / \mathrm{d}(0.63) \\
\text { Women } 1.64 \mathrm{~kg} / \mathrm{d}(0.51)\end{array}$ & \\
\hline Switzerland (Haveman-Nies et & $75-80$ & Men $1.98 \mathrm{~kg} / \mathrm{d}(0.51)$ & \\
\hline
\end{tabular}




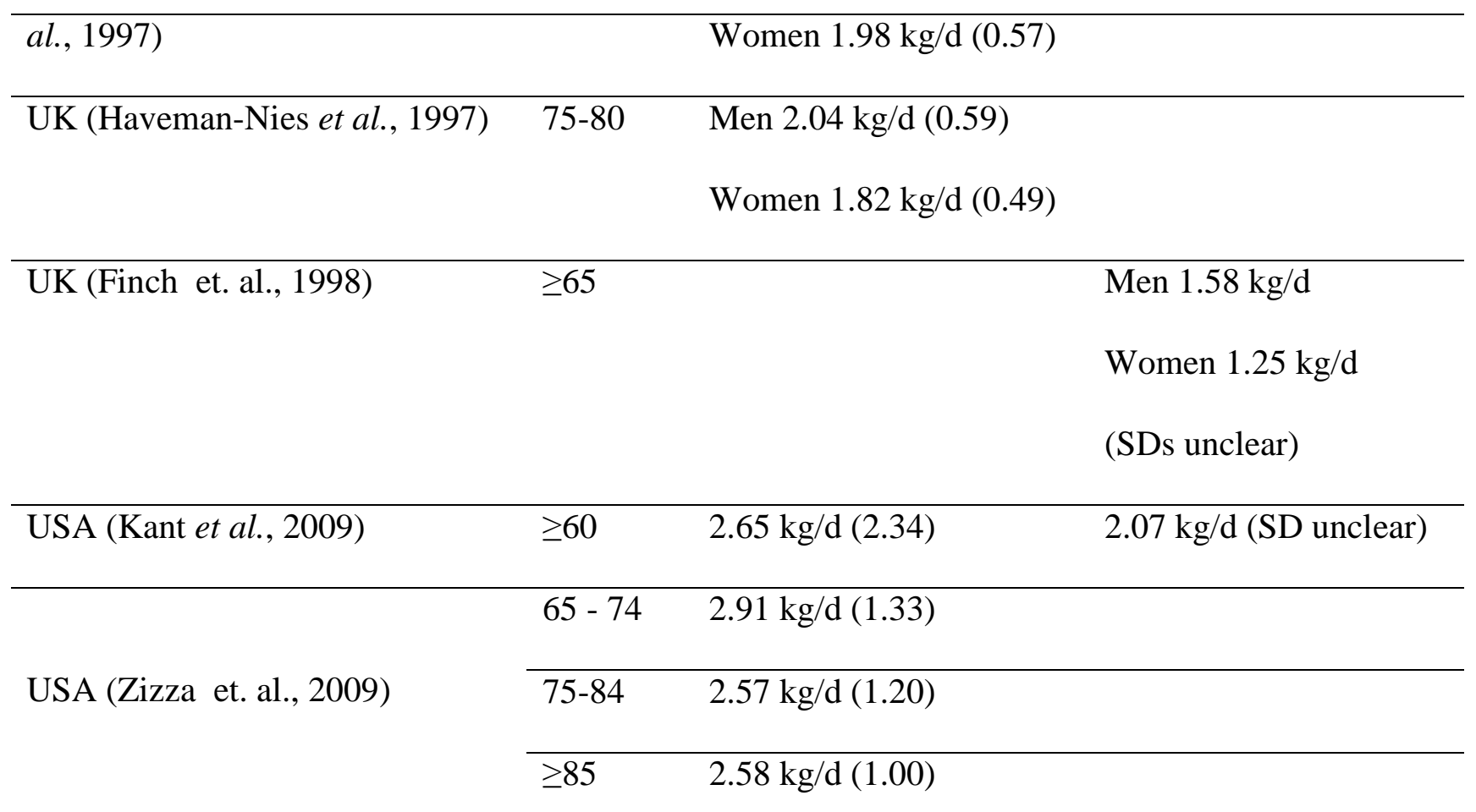

*Total water includes fluid from drinks and foods.

Elderly people living in long-term care tend to drink less and have less variety of drinks than their community-dwelling counterparts (Adams, 1988;Mentes and Iowa-Veterans Affairs Research, 2000). In the US, institutionalised elderly people were reported to have lower mean daily fluid intake (food and drink) of 1.51L/day compared with $2.12 \mathrm{~L} /$ day in their non-institutionalised counterparts (Adams, 1988). In the UK free-living people aged 65 and over drank $1.30 \mathrm{~L} / \mathrm{d}$ compared to $1.16 \mathrm{~L} / \mathrm{d}$ in those living in institutions (Finch et al., 1998), and a deuterium oxide tracer study found that in summer median fluid intake was $2.2 \mathrm{~L} / \mathrm{d}$ (range 1.3-3.6L/d) in older people living in the community, and $1.5 \mathrm{~L} / \mathrm{d}(0.9$ to $2.9 \mathrm{~L} / \mathrm{d})$ in those living in institutions (Leiper et. al., 2005).

Measuring fluid intake accurately is a challenge. A wide range of methods including deuterium oxide dilution, dietary records, direct observation, food frequency questionnaires, 24 hour recalls, photography and fluid charts have all been used to measure how much older people drink (Adams, 1988;Armstrong-Esther et. al., 1996;Simmons and Reuben, 2000). Choice of method is dependent on the setting, population and study objectives (Thompson and Subar, 2008;Van Staveren et. al., 
1994). Water is sometimes measured independently, as part of other beverages or in both food and drink (Andrews and Castellanos, 2003;Armstrong-Esther et al., 1996;Simmons et al., 2000).

Deuterium oxide dilution is considered the reference standard method (Leiper et al., 2005), although direct observation, utilising weighed or estimated amount consumed (Armstrong-Esther et al., 1996; Wu et. al., 2010) is more commonly used. Direct observation, while cheaper than deuterium dilution, is still burdensome and limited by the literacy and motivation of participants (Rutishauser, 2005; Thompson et al., 2008). The food frequency questionnaire (a simplified dietary record, relying on estimated frequency of specific drinks (Rutishauser, 2005) is easy to complete but some drinks may be under-declared because of social pressures (Bellisle et al., 2010). For 24-hour dietary recall participants are asked to remember and report fluids consumed in the last 24 hours, through a structured interview. For some elderly people however, recall may be limited. Fluid charts are used by staff in some residential homes and hospitals to measure fluid intake over 24 hours (Scales and Pilsworth, 2008), but many are not completed accurately in hospital (Reid et. al., 2004) or care homes (Kayser-Jones et al., 1999). Use of dietary surveys to assess fluid intake has been questioned as dietary surveys are often designed mainly to record food intake rather than drinking occasions, so may underestimate fluid intake, especially drinks between meals (Vergne, 2012).

Measuring fluid intake is a challenge, especially in older people, and the use of different methods and different standards makes the comparison of results from different studies difficult. The use of methods aimed at measuring energy and nutrient may underestimate fluid intake, therefore fluidspecific methods capable of capturing complete fluid intake data needs to be developed and used for fluid intake studies. 


\subsection{The effect of water-loss dehydration on the health of older people}

We know that water-loss dehydration is associated with many chronic health problems in older people, including falls, fractures, confusion, delirium, pressure ulcers, poor wound healing, constipation, urinary tract infections, heat stress, infections, kidney stones, renal failure, drug toxicity, stroke and myocardial infarction (Chan et. al., 2002;Olde Rikkert et al., 2009;Rolland et. al., 2006; Thomas et al., 2008; Wakefield et. al., 2008). Extreme dehydration is an emergency medical condition requiring rapid re-hydration to prevent hypovolaemic shock. The signs of hypovolaemic shock include being cool and clammy, having reduced urine output, flat neck veins, altered mental status, low pulmonary wedge pressure, low cardiac index and high systemic vascular resistance index. $17 \%$ of those admitted to hospital with a main diagnosis of dehydration die within 30 days (Waikar et. al., 2009).

We could find no research exploring the costs of dehydration in Europe, but in 1999 the US estimated avoidable cost to healthcare of older people (aged at least 65) admitted to hospital with a primary diagnosis of dehydration was $\$ 1.1$ to $\$ 1.4$ billion per year and these hospitalisation rates appear to be rising (Xiao et. al., 2004). For example, a more recent US analysis suggests that in 2004 the US costs for admission with dehydration in people of all ages was $\$ 5.5$ billion per year (Kim, 2007).

Prospective studies that adjusted appropriately for concurrent risk factors and disease have suggested that raised serum osmolality and/or tonicity are associated with increased risk of mortality in a general elderly US population, UK stroke patients and US older people with diabetes, and that raised tonicity is associated with poorer functional status in US older people (Bhalla et. al., 2000;Stookey et. al., 2004; Wachtel et. al., 1991). For example, in 561 non-disabled people aged at least 70 years increased tonicity ( $\geq 300 \mathrm{mOsm} / \mathrm{L})$ compared to normal tonicity $(285-294 \mathrm{mOsm} / \mathrm{L})$ was associated with increased risk of disability at 4 years (RR 2.1, 95\% CI 1.2 to 3.6) (Stookey et al., 2004). Since 
one of the reasons for increased tonicity may be uncontrolled diabetes, the analysis was carried out after removing those with raised glucose, and a very similar, though non-statistically significant risk of 4-year disability (as the sample was no longer large enough, RR 1.8, 95\% CI 0.8-3.9 in normoglycaemics) was observed. This analysis controlled for age, sex, race, weight, smoking, activity, plasma urea and creatinine, cognitive impairment, depression, and chronic disease. The relationship between raised tonicity and mortality at 8 years was also assessed, finding an increased risk of 8-year mortality (RR 1.4, 95\% CI 1.0-1.9) with a similar relative risk in normoglycaemics, although no longer statistically significant (RR 1.5, 95\% CI 0.9-2.3 in normoglycaemics) (Stookey et al., 2004).

\subsection{Research needed in dehydration and older people}

Further research is required in this area. We need to develop ways of screening for early stage dehydration in the elderly, and develop best practice for helping older people to consume sufficient liquids in care homes and in the community. Older people and their carers (both formal and informal) require training to recognise early signs of dehydration and we need strategies for promoting drinking. As part of this we must better understand fluid intake variability in older people, and daily fluid intakes associated with adequate hydration status. Finally, it is crucial that we test whether increasing the fluid intake in older people improves outcomes in terms of mortality, morbidity and quality of life.

The NU-AGE (FP7-funded "New dietary strategies addressing the specific needs of elderly population for a healthy ageing in Europe") trial will enable us to assess the effect of the dietary intervention on fluid intake, as well as to study the relationship between fluid intake and hydration status in a community-based older population in greater depth than has been achieved in the past. We will use dietary intake data and serum samples to describe the relationship between fluid intake 
and dehydration status - to define fluid intake needs in older people. We will also describe characteristics (drinking frequency, type, variety, daily and seasonal variability, alcohol intake, age, gender) and dietary patterns associated with good hydration. We plan to use these results to work with older adults and their carers to develop information and educational materials to ensure that older people know how to achieve healthy fluid intakes.

Box 1. Serum measures of hydration status (potential gold standards for dehydration)

口 Serum Osmolality is measured using the freezing point of serum $(\mathrm{mOsm} / \mathrm{kg})$

口 Serum Osmolarity $(\mathrm{mOsm} / \mathrm{L})$ is calculated by summing components:

- $2 \mathrm{Na}+2 \mathrm{~K}+$ glucose + urea (all in $\mathrm{mmol} / \mathrm{L}) *$

口 Serum Tonicity (mOsm/L) (or effective osmolarity) is calculated:

- $2 \mathrm{Na}+2 \mathrm{~K}+$ glucose (all in $\mathrm{mmol} / \mathrm{L}$ )

Serum Sodium may be used as a proxy for osmolality or tonicity

*This is one formula for osmolarity but there are many more (Fazekas et. al., 2013) 
Figure 1. The mechanism of fluid conservation following reduced drinking

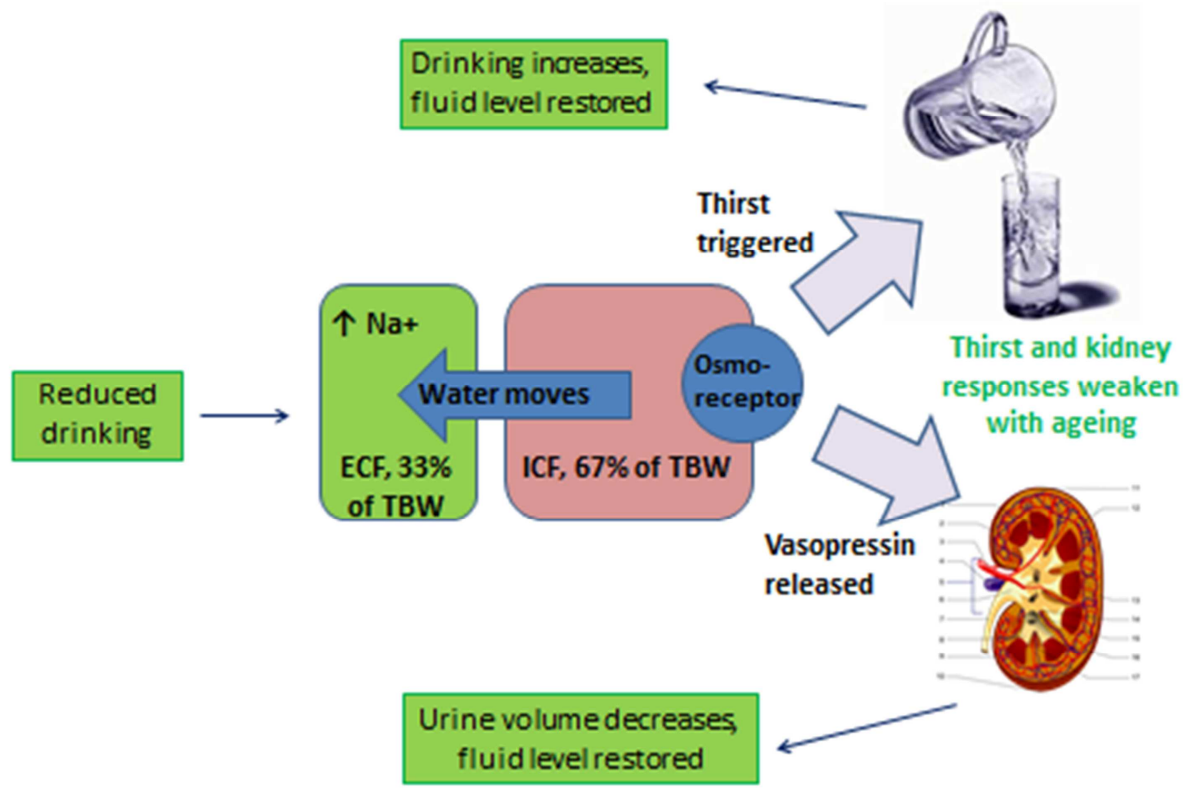

ICF: intracellular fluid, ECF: extracellular fluid, TBW: total body water. Under normal circumstances reducing fluid intake raises extracellular sodium, raising osmolality. Water moves into the extracellular spaces from within cells to equalise osmolality. This means that cells shrink slightly and osmolality rises within the cells, stimulating the osmoreceptors. Osmoreceptors stimulate thirst, leading to increased drinking and vasopressin release which stimulates fluid conservation by the kidney. These lead to restoration of fluid in the body. 


\subsection{References}

1. Adams, F., 1988. How much do elders drink? Geriatr. Nurs 9, 218-221.

2. Altman, P.L., 1961. Blood and Other Body Fluids. Federation of American Societies for Experimental Biology, Washington, DC.

3. American Medical Directors Association (AMDA). Dehydration and fluid maintenance in the long-term care setting. 1-29. 2009. Columbia (MD), USA, American Medical Directors Association (AMDA).

4. Andrews, Y.N., Castellanos, V.H., 2003. Development of a method for estimation of food and fluid intakes by nursing assistants in long-term care facilities: A pilot study. J Am. Diet. Assoc 103, 873-877.

5. Anglian Water Services. Health on tap - a campaign to promote good hydration in older people in residential care from Anglian Water.

http://www.anglianwater.co.uk/_assets/media/health-on-tap-good-hydration-report.pdf . 2009. Huntingdon. 4-11-2013.

6. Aristotle, 350 B.C. On Longevity and Shortness of Life. Internet Classics Archive.

7. Armstrong, L.E., 2007. Assessing Hydration Status: The Elusive Gold Standard. J Am. Coll. Nutr. 26, 575S-584S.

8. Armstrong-Esther, C.A., Browne, K.D., Armstrong-Esther, D.C., Sander, L., 1996. The institutionalized elderly: Dry to the bone! International Journal of Nursing Studies 33, 619628.

9. Australian Government, 2006. Nutrient Reference Values for Australia and New Zealand Including Recommended Dietary Intakes. NHMRC: : Department of Health and Ageing,National Health and Medical Research Council, Canberra.

10. Bellisle, F., Thronton, S.N., Hebel, P., Denizeau, P., Tahiri, M., 2010. A study of fluid intake from beverages in a sample of health French children, adolescent and adults. Eur. J Clin. Nutr. 64, 350-355.

11. Bhalla, A., Sankaralingam, S., Dundas, R., Swaminathan, R., Wolfe, C.D., Rudd, A.G., 2000. Influence of raised plasma osmolality on clinical outcome after acute stroke. Stroke 31, 20432048.

12. Bourre, J.M., 2006. Effects of nutrients (in food) on the structure and function of the nervous system: update on dietary requirements for brain. Part 1: micronutrients. J Nutr. Health Aging $10,377-385$.

13. Bunn, D., Hooper, L. Effectiveness of external factors to reduce the risk of dehydration in older people living in residential care: a systematic review. PROSPERO 2012:CRD42012003100 Available from http://www.crd.york.ac.uk/PROSPERO/display_record.asp?ID=CRD42012003100 . 2012.

14. Campbell, N., 2011. Dehydration: why is it still a problem? Nurs Times 107, 12-15. 
15. Chan, J., Knutsen, S.F., Blix, G.G., Lee, J.W., Fraser, G.E., 2002. Water, other fluids, and fatal coronary heart disease: The Adventist health study. Am. J Epidemiol. 155, 827-833.

16. Cheuvront, S.N., Ely, B.R., Kenefick, R.W., Sawka, M.N., 2010. Biological variation and diagnostic accuracy of dehydration assessment markers. Am. J Clin. Nutr. 92, 565-573.

17. Cheuvront, S.N., Kenefick, R.W., Charkoudian, N., Sawka, M.N., 2013. Physiologic basis for understanding quantitative dehydration assessment. Am. J Clin. Nutr. 97, 455-462.

18. Davies, D.F., Shock, N.W., 1950. Age changes in glomerular filtration rate, effective renal plasma flow, and tubular excretory capacity in adult males. J Clin Invest 29, 496-507.

19. Davies, I., O'Neill, P.A., McLean, K.A., Catania, J., Bennett, D., 1995. Age-associated Alterations in Thirst and Arginine Vasopressin in Response to a Water or Sodium Load. Age Ageing 24, 151-159.

20. Devriese, S., Huybrechts, I., Moreau, M., Van Oyen, H. De Belgische Voedselconsumptiepeiling 1 - 2004. D/2006/2505/17, IPH/EPI REPORTS Nº 2006 - 016 (at https://www.wiv-isp.be/epidemio/epinl/foodnl/table04.htm). 2006. Brussel, Wetenschappelijk Instituut Volksgezondheid.

21. Dickinson, A., Welch, C., Ager, L., 2008. No longer hungry in hospital: improving the hospital mealtime experience for older people through action research. J Clin Nurs 17, 14921502.

22. Dunne, T., Neargarder, S., Cipolloni, P., Cronin-Golomb, A., 2004. Visual contrast enhances food and liquid intake in advanced Alzheimer's disease. Clin. Nutr. 23, 533-538.

23. Dupin, H., Abraham, J., Giachetti, I., 1992. Apports nutritionelles conseilles pour la population francaise. Tec \& Doc Lavoisier, Paris.

24. EFSA Panel on Dietetic Products, N.a.A.N., 2010. Scientific Opinion on Dietary reference values for water. EFSA Journal 8, 1459.

25. Fazekas, A.S., Funk, G.-C., Klobassa, D.S., Ruther, H., Ziegler, I., Zander, R., Semmelrock, H.-J., 2013. Evaluation of 36 formulas for calculating plasma osmolality. Intensive Care Med. 39, 302-308.

26. Finch, S., Doyle, W., Lowe, C., Bates, C.J., Prentice, A., Smithers, G., Clarke, P.C., 1998. National Diet and Nutrition Survey: people aged 65 years and over. Volume 1: Report of the diet and nutrition survey. TSO, London.

27. Friedman, J.N., Goldman, R.D., Srivastava, R., Parkin, P.C., 2004. Development of a clinical dehydration scale for use in children between 1 and 36 months of age. J Pediatr 145, 201-207.

28. Friis-Hansen, B.J., Holiday, M., Stapleton, T., Wallace, W.M., 1951. Total body water in children. Pediatrics 7, 321-327.

29. Gleibs, I., Haslam, C., Haslam, S.A., Jones, J., 2011. Water clubs in residential care: Is it the water or the club that enhances health and well-being? Psychology \& Health 26, 1361-1377. 
30. Godfrey, H., Cloete, J., Dymond, E., Long, A., 2012. An Exploration of the hydration care of older people: a qualitative study. International Journal of Nursing Studies 49, 1200-1211.

31. Goldman, R.D., Friedman, J.N., Parkin, P.C., 2008. Validation of the clinical dehydration scale for children with acute gastroenteritis. Pediatrics 122, 545-549.

32. Gorelick, M.H., Shaw, K.N., Murphy, K.O., 1997. Validity and reliability of clinical signs in the diagnosis of dehydration in children. Pediatrics 99, E6.

33. Greenleaf, J.E., 1998. Stress, aging and thirst. In: Vellas, B., Albarede, J.L., Garry, P.J. (Eds.), Hydration and aging Serdi, Paris, pp. 47-58.

34. Gross, C.R., Lindquist, R.D., Woolley, A.C., Granieri, R., Allard, K., Webster, B., 1992. Clinical indicators of dehydration severity in elderly patients. J Emerg. Med 10, 267-274.

35. Haveman-Nies, A., de Groot, L.C., Van Staveren, W.A., 1997. Fluid intake of elderly Europeans. The journal of nutrition, health \& aging 1, 151-155.

36. Hodgkinson, B., Evans, D., Wood, J., 2003. Maintaining oral hydration in older adults: a systematic review. Int. J Nurs. Pract. 9, S19-S28.

37. Hollis, S., 2011. Using red jugs to improve hydration. Nurs Times 107, 28.

38. Hooper, L., Culp, K.R., Stookey, J.D., Ritz, P., Campbell, W.W., Mack, G.W., Fletcher, S.J., Potter, J.F., Hunter, P., Lindner, G., Mentes, J., Olde Rikkert, M.G.M., Thomas, D.R., Gaspar, P.M., Wakefield, B., Chassagne, P., Attreed, T., Channell, A., Gilbert, D., Heathcote, A., Needham, R.A., Ranson, S., Smith, A., Ward, S., 2011. Clinical and physical signs for identification of impending and current water-loss dehydration in older people. The Cochrane Library Protocol, CD009647-DOI:10.1002/14651858.

39. Institute of Medicine, 2004. Panel on Dietary Reference Intakes for Electrolytes and Water. Dietary Reference Intakes for Water, Potassium, Sodium, Chloride, and Sulfate. National Academies Press, Washington DC, USA.

40. Kafri, M.W., Myint, P.K., Doherty, D., Wilson, A.H., Potter, J.F., Hooper, L., 2013. The diagnostic accuracy of multi-frequency bioelectrical impedance analysis in diagnosing dehydration after stroke. Med. Sci. Monit. 19, 548-570.

41. Kant, A.K., Graubard, B.I., Atchison, E.A., 2009. Intakes of plain water, moisture in foods and beverages, and total water in the adult US population--nutritional, meal pattern, and body weight correlates: National Health and Nutrition Examination Surveys 1999-2006. Am. J Clin. Nutr. 90, 655-663.

42. Kayser-Jones, J., Schell, E.S., Porter, C., Barbaccia, J.C., Shaw, H., 1999. Factors contributing to dehydration in nursing homes: Inadequate staffing and lack of professional supervision. J Am. Geriatr. Soc. 47, 1187-1194.

43. Kenkmann, A., Price, G.M., Bolton, J., Hooper, L., 2010. Health, wellbeing and nutritional status of older people living in UK care homes: an exploratory evaluation of changes in food and drink provision. BMC Geriatr. 10, 28. 
44. Kim, S., 2007. Preventable Hospitalizations of Dehydration: Implications of Inadequate Primary Health Care in the United States. Ann. Epidemiol. 17, 736.

45. Kyle, U.G., Bosaeus, I., De Lorenzo, A.D., Deurenberg, P., Elia, M., Gomez, J.M., et al, 2004. Bioelectrical impedance analysis. Part I: review of principles and methods. Clin. Nutr. $23,1226-1243$.

46. Leibovitz, A., Baumoehl, Y., Lubart, E., Yaina, A., Platinovitz, N., Segal, R., 2007. Dehydration among long-term care elderly patients with oropharyngeal dysphagia. Gerontology 53, 179-183.

47. Leiper, J.B., Seonaid, P.C., Primrose, W.R., Phillimore, J., Maughan, R.J., 2005. A comparison of water turnover in older people in community and institutional settings. J Nutr. Health Aging 9, 189-193.

48. Lindeman, R.D., Tobin, J.N., Shock, N.W., 1985. Longitudinal studies on the rate of decline in renal function with age. J Am. Geriatr. Soc. 33, 278-285.

49. Mack, G.W., Weseman, C.A., Langhans, G.W., Scherzer, H., Gillen, C.M., Nadel, E.R., 1994. Body fluid balance in dehydrated healthy older men: Thirst and renal osmoregulation. J Appl. Physiol 76, 1615-1623.

50. Manz, F., Johner, S.A., Wentz, A., Boeing, H., Remer, T., 2012. Water balance throughout the adult life span in a German population. Br J Nutr 107, 1673-1681.

51. Martin, A.D., Daniel, M.Z., Drinkwater, D.T., Clarys, J.P., 1994. Adipose tissue density, estimated adipose lipid fraction and whole body adiposity in male cadavers. Int J Obes Relat Metab Disord 18, 79-83.

52. McGee, S., Abernethy, W.B., Simel, D.L., 1999. Is this patient hypovolemic? Journal of the American Medical Association 281, 1022-1029.

53. Mentes, J., 2006. Oral hydration in older adults: greater awareness is needed in preventing, recognizing, and treating dehydration. Am. 106, 40-49.

54. Mentes, J.C., Iowa-Veterans Affairs Research, C., 2000. Hydration management protocol. J Gerontol. Nurs. 10, 6-15.

55. Mentes, J.C., Wakefield, B., Culp, K.R., 2006. Use of a urine color chart to monitor hydration status in nursing home residents. Biol Res Nurs 7, 197-203.

56. Naitoh, M., Burrell, L.M., 1998. Thirst in elderly subjects. In: Vellas, B., Albarede, J.L., Garry, P.J. (Eds.), Hydration and aging Serdi, Paris, pp. 33-46.

57. NHS Choices. Water and drinks. http://www.nhs.uk/Livewell/Goodfood/Pages/waterdrinks.aspx . 2011. 8-4-2013.

58. NNR. Draft Nordic Nutrition Recommendations: Fluid and water balance. http://www.slv.se/en-gb/Startpage-NNR/Public-consultation/ . 2012.

59. Olde Rikkert, M.G., Deurenberg, P., Jansen, R.W., van't Hof, M.A., Hoefnagels, W.H., Olde Rikkert, M.G., Deurenberg, P., Jansen, R.W., van't Hof, M.A., Hoefnagels, W.H., 1997. 
Validation of multi-frequency bioelectrical impedance analysis in detecting changes in fluid balance of geriatric patients. J Am. Geriatr. Soc. 45, 1345-1351.

60. Olde Rikkert, M.G.M., Hoefnagels, W.H.L., Deurenberg, P., 1998. Age-related changes in body fluid compartments and the assessment of dehydration in old age. In: Vellas, B., Albarede, J.L., Garry, P.J. (Eds.), Hydration and Aging Serdi, Paris, pp. 9-32.

61. Olde Rikkert, M.G.M., Melis, R.J.F., Claassen, J.A.H.R., 2009. Heat waves and dehyration in the elderly: recognising the early warning signs can save lives. BMJ 339, b2663.

62. Philpin, S., Merrell, J., Warring, J., Gregory, V., Hobby, D., 2011. Sociocultral context of nutrition in Care Homes. Nurs Older People 23, 24-30.

63. Pietruszka, B., Krajewska, M., 2003. Assessment of total water and beverage intake by the elderly living in Warsaw region. 12/53, 69-72.

64. Reid, J., Robb, E., Stone, D., Bowen, P., Baker, R., Irving, S., Waller, M., 2004. Improving the monitoring and assessment of fluid balance. 20, 36-39.

65. Robinson, S.B., Rosher, R.B., 2002. Can a beverage cart help improve hydration? Geriatr. Nurs 23, 208-211.

66. Rochon, P.A., Gill, S.S., Litner, J., Fischbach, M., Goodison, A.J., Gordon, M., 1997. A systematic review of the evidence for hypodermoclysis to treat dehydration in older people. $\mathrm{J}$ Gerontol A Biol Sci Med Sci 52, M169-M176.

67. Rolland, Y., Kim, M.J., Gammack, J.K., Wilson, M.M., Thomas, D.R., Morley, J.E., 2006. Office management of weight loss in older persons. Am. J Med. 119, 1019-1026.

68. Rowe, J.W., Shock, N.W., Defronzo, R.A., 1976. The influence of age on the renal response to water deprivation in man. Nephron 17, 270-278.

69. Rutishauser, I.H., 2005. Dietary intake measurements. Public Health Nutr England, pp. 11001107.

70. Sands, J.M., 2009. Urinary concentration and dilution in the aging kidney. Semin Nephrol 29, 579-586.

71. Scales, K., Pilsworth, J., 2008. The importance of fluid balance in clinical practice. 22, 50-57.

72. Schloerb, P.R., Friis-Hansen, B.J., Edelman, I.S., Soloman, A.K., Moore, F.D., 1950. The measurement of total body water in the human subject by deuterium oxide dilution. Journal of Clinical Investigation 29, 1296-1310.

73. Schut, A., Dascendo, V., Giraud, K., Chatap, G., Royand, F., Blonde-Cynober, F., Aussel, C., Vincent, J.P., Schut, A., Dascendo, V., Giraud, K., Chatap, G., Royand, F., Blonde-Cynober, F., Aussel, C., Vincent, J.P., 2005. Is biolectrical impedance analysis a tool at bedside, during heat waves to assist geriatricians with discriminative diagnosis of hypertonic dehydration? $\mathrm{J}$ Nutr. Health Aging 9, 441-445. 
74. Seymour, D.G., Henschke, P.J., Cape, R.D.T., Campbell, A.J., 1980. Acute confusional states and dementia in the elderly: the role of dehydration/volume depletion, physical illness and age. Age and Ageing 9, 137-146.

75. Shimizu, M., Kinoshita, K., Hattori, K., Ota, Y., Kanai, T., Kobayashi, H., Tokuda, Y., 2012. Physical signs of dehydration in the elderly. Intern Med 51, 1207-1210.

76. Shirreffs, S.M., 2003. Markers of hydration status. Eur. J Clin. Nutr. 57, S6-S9.

77. Simmons, S.F., Alessi, C., Schnelle, J.F., 2001a. An intervention to increase fluid intake in nursing home residents: prompting and preference compliance. J Am. Geriatr. Soc. 49, 926933.

78. Simmons, S.F., Osterweil, D., Schnelle, J.F., 2001b. Improving food intake in nursing home residents with feeding assistance: a staffing analysis. J Gerontol. A Biol. Sci. Med. Sci. 56, M790-M794.

79. Simmons, S.F., Reuben, D., 2000. Nutritional intake monitoring for nursing home residents: a comparison of staff documentation, direct observation, and photography methods. J Am. Geriatr. Soc. 2, 209-213.

80. Solemdal, K., Sandvik, L., Willumsen, T., Mowe, M., Hummel, T., 2012. The impact of oral health on taste ability in acutely hospitalized elderly. PLoS ONE 7, e36557.

81. Steiner, M.J., DeWalt, D.A., Byerley, J.S., 2004. Is this child dehydrated? JAMA 291, 27462754.

82. Stookey, J.D., 2005. High prevalence of plasma hypertonicity among community-dwelling older adults: results from NHANES III. J Am. Diet. Assoc 105, 1231-1239.

83. Stookey, J.D., Pieper, C.F., Cohen, H.J., 2005. Is the prevalence of dehydration among community-dwelling older adults really low? Informing current debate over the fluid recommendation for adults aged 70+years. Public Health Nutr. 8, 1275-1285.

84. Stookey, J.D., Purser, J.L., Pieper, C.F., Cohen, H.J., 2004. Plasma hypertonicity: Another marker of frailty? J Am. Geriatr. Soc. 52, 1313-1320.

85. Thomas, D.R., Cote, T.R., Lawhorne, L., Levenson, S.A., Rubenstein, L.Z., Smith, D.A., Stefanacci, R.G., Tangalos, E.G., Morley, J.E., Dehydration Council, 2008. Understanding clinical dehydration and its treatment. J AM. MED. DIR. ASSOC. 9, 292-301.

86. Thomas, D.R., Tariq, S.H., Makhdomm, S., Haddad, R., Moinuddin, A., 2003. Physician misdiagnosis of dehydration in older adults. J AM. MED. DIR. ASSOC. 4, 251-254.

87. Thompson, F.E., Subar, A.F., 2008. Nutrition in the prevention and treatment of Disease. Academic Press, San Diego.

88. Ullrich, S., McCutcheon, H., 2008. Nursing practice and oral fluid intake of older people with dementia. J Clin Nurs 17, 2910-2919.

89. Van Staveren, W.A., de Groot, L.C., Blauw, Y.H., van der Wielen, R.P.J., 1994. Assessing diets of elderly people: problems and approaches. Am. J Clin. Nutr. 59, 221S-223S. 
90. Vergne, S.Ã., 2012. Methodological Aspects of Fluid Intake Records and Surveys. 47, S7S10.

91. Vivanti, A., 2012. Origins for the estimations of water requirements in adults. Eur. J Clin. Nutr. 66, 1282-1289.

92. Vivanti, A., Harvey, K., Ash, S., Battistutta, D., 2008. Clinical assessment of dehydration in older people admitted to hospital: what are the strongest indicators? Arch Gerontol. Geriatr. 47, 340-355.

93. Wachtel, T.J., Tetu-Mouradjian, L.M., Goldman, D.L., Ellis, S.E., O'Sullivan, P.S., 1991. Hyperosmolarity and acidosis in diabetes mellitus: a three-year experience in Rhode Island. J Gen. Intern. Med. 6, 495-502.

94. Waikar, S.S., Mount, D.B., Curhan, G.C., 2009. Mortality after hospitalization with mild, moderate, and severe hyponatremia. Am. J Med. 122, 857-865.

95. Wakefield, B.J., Mentes, J., Holman, J.E., Culp, K., 2008. Risk factors and outcomes associated with hospital admission for dehydration. Rehabilitation Nursing 33, 233-241.

96. Walsh, N.P., Fortes, M.B., Raymond-Barker, P., Bishop, C., Owen, J., Tye, E., Esmaeelpour, M., Purslow, C., Elghenzai, S., 2012. Is whole-body hydration an important consideration in dry eye? Investigative Ophthalmology and Visual Science 53, 6622-6627.

97. Warren, J.L., Bacon, W.E., Harris, T., McBean, A.M., Foley, D.J., Phillips, C., Warren, J.L., Bacon, W.E., Harris, T., McBean, A.M., Foley, D.J., Phillips, C., 1994. The burden and outcomes associated with dehydration among US elderly, 1991. Am. J Public Health 84, 1265-1269.

98. Weinberg, A.D., Minaker, K.L., Allen, J.R., Coble, J., Davis, R.M., Head, C.A., Howe III, J.P., Karlan, M.S., Kennedy, W.R., Numann, P.J., Spillman, M.A., Skelton, W.D., Steinhilber, R.M., Strong, J.P., Wagner, J., 1995. Dehydration: Evaluation and management in older adults. Journal of the American Medical Association 274, 1552-1556.

99. World Health Organization, 2005. Nutrients in drinking water. WHO (http://www.who.int/water_sanitation_health/dwq/nutrientsindw.pdf), Geneva.

100. Wotton, K., Crannitch, K., Munt, R., 2008. Prevalence, risk factors and strategies to prevent dehydration in older adults. Contemporary nurse : a journal for the Australian nursing profession 31, 44-56.

101. Wu, S.J., Wang, H.H., Yeh, S.H., Wang, Y.H., Yang, Y.M., 2010. Hydration status of nursing home residents in Taiwan: a cross-sectional study. Journal of Advanced Nursing 67, 583-590.

102. Xiao, H., Barber, J., Campbell, E.S., 2004. Economic burden of dehydration among hospitalized elderly patients. Am J Health Syst Pharm 61, 2534-2540.

103. Zizza, C.A., Ellison, K.J., Wernette, C.M., 2009. Total Water Intakes of Community-Living Middle-Old and Oldest-Old Adults. 64A, 481-486. 